\title{
Management of acute cholecystitis in patient with cyclic neutropenia: a case report
}

\author{
Saki Nishikawa ${ }^{1,2}$, Michinori Hamaoka ${ }^{1,2^{*}}$ (D) Hideki Nakahara ${ }^{1,2}$ and Toshiyuki Itamoto ${ }^{1,2}$
}

\begin{abstract}
Background: Cyclic neutropenia is a disease that causes a neutropenic decrease in peripheral blood in a cycle of about 21 days. It is a rare hereditary disorder with an estimated incidence of $0.5-1$ cases per million population. The absolute neutrophil count can drop to zero, and neutropenic nadir may last for 3-5 days. This is a rare disease, and there are few reports of abdominal surgery in cyclic neutropenia patients; thus, we report this case of neutrophil count fluctuation and perioperative management.
\end{abstract}

Case presentation: A 31-year-old man with cyclic neutropenia was transferred to our hospital complaining of right season rib pain, but no rebound tenderness. His C-reactive protein was elevated $(4.37 \mathrm{mg} / \mathrm{L})$ and computed tomography revealed a large number of small stones in the gallbladder body and an incarceration in the gallbladder neck. He was diagnosed with acute cholecystitis. Ideally, surgical intervention should have been performed immediately, but because his neutrophil count was 300/ $\mu \mathrm{L}$, endoscopic naso-gallbladder drainage was performed and he was provided antibiotics until his neutrophil count increased to acceptable levels. Three days after admission, his neutrophil count had increased and laparoscopic cholecystectomy was performed. For one week after the operation, antibiotics were administered; he had an uneventful postoperative recovery. He was discharged on the seventh postoperative day and provided an oral antibiotic.

Conclusions: Infection can be serious in patients with cyclic neutropenia, and it is therefore, important to determine the timing of surgery and to apply appropriate perioperative management with drainage and antibiotic administration.

Keywords: Acute cholecystitis, Cyclic neutropenia, Laparoscopic cholecystectomy, Operation, Surgery

\section{Background}

Cyclic neutropenia is a disease that causes a neutropenic decrease in peripheral blood in a cycle of about 21 days. It is a rare hereditary disorder with an estimated incidence of $0.5-1$ cases per million population and there is no gender difference in the incidence [1]. Familial cases of autosomal dominant inheritance have been reported, and it may be caused by the neutrophil elastase gene (ELA2) mutation. The absolute neutrophil count can drop to zero, and neutropenic nadir may last for 3 to 5 days [2].

\footnotetext{
*Correspondence: oosaji5hai@yahoo.co.jp

${ }^{1}$ Department of Surgery, Hiroshima Prefectural Hospital, 1-5-54

Ujina-Kanda, Minami-ku, Hiroshima 734-8530, Japan

Full list of author information is available at the end of the article
}

The most common infections are pharyngitis, gingivitis, and periodontitis during neutropenic nadir, but serious symptoms can occur during neutropenia [1]. Perioperative complications can be fatal for these patients; hence, perioperative management requires particular attention. Moreover, though acute cholecystitis is a common disease of the abdomen, its clinical manifestation can be severe. The symptoms may be more severe during neutropenia in these patients; therefore, it is important to determine the timing of surgery considering the change in absolute neutrophil count and perform more careful perioperative management. 


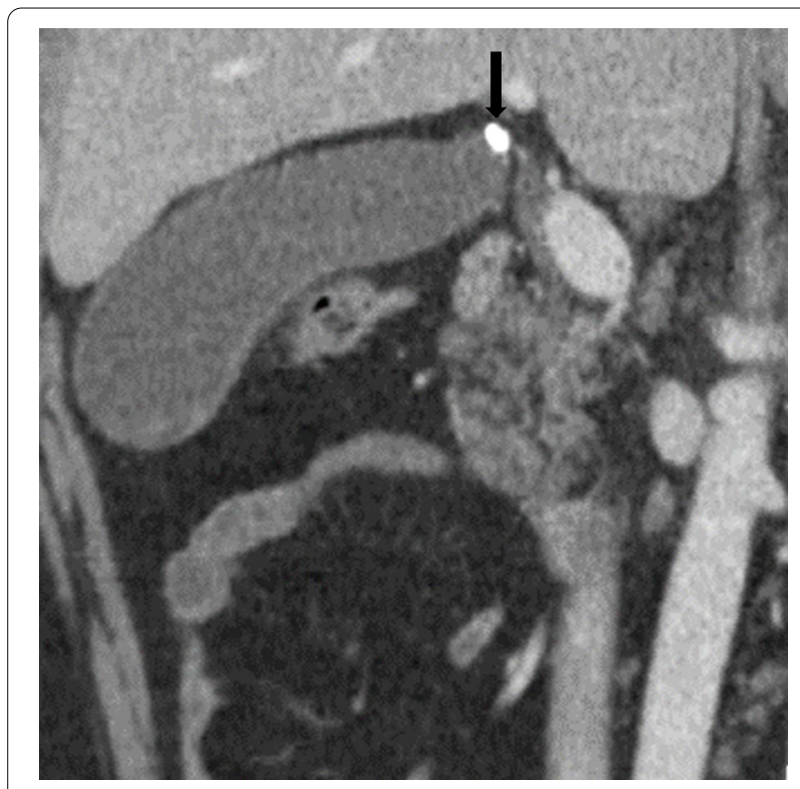

Fig. 1 Computed tomography. Arrow indicates incarceration of a small in the neck of the gallbladder

\section{Case presentation}

A 31-year-old man with cyclic neutropenia was transferred to our hospital complaining of right side rib pain.
He was diagnosed with the disease in early childhood and his neutrophil count varied from 0 to $40 \%$ (0-3000/ $\mu \mathrm{L})$ in a cycle of approximately 21 days. During neutropenic nadir, he had a fever and aphthous stomatitis, but these symptoms improved in a few days. When his symptoms were severe, he was occasionally prescribed antibiotics and granulocyte colony-stimulating factor (G-CSF). He presented with pain from the epigastric region to the right season rib, but no recoil. His C-reactive protein (CRP) was elevated $(4.37 \mathrm{mg} / \mathrm{L})$ and computed tomography $(\mathrm{CT})$ revealed a large number of small stones in the gallbladder body and an incarceration in the gallbladder neck (Fig. 1). He was diagnosed with acute cholecystitis. His white blood cell count was $3300 / \mu \mathrm{L}$ and neutrophil count was $300 / \mu \mathrm{L}$. Endoscopic naso-gallbladder drainage (ENGBD) was performed, and antibiotics were administered. Three days after admission, his neutrophil count increased (Fig. 2), and laparoscopic cholecystectomy was performed. For 1 week after the operation, antibiotics were instilled, and he had an uneventful postoperative recovery; this was changed to an oral antibiotic on his discharge on the 7 th day after the operation.

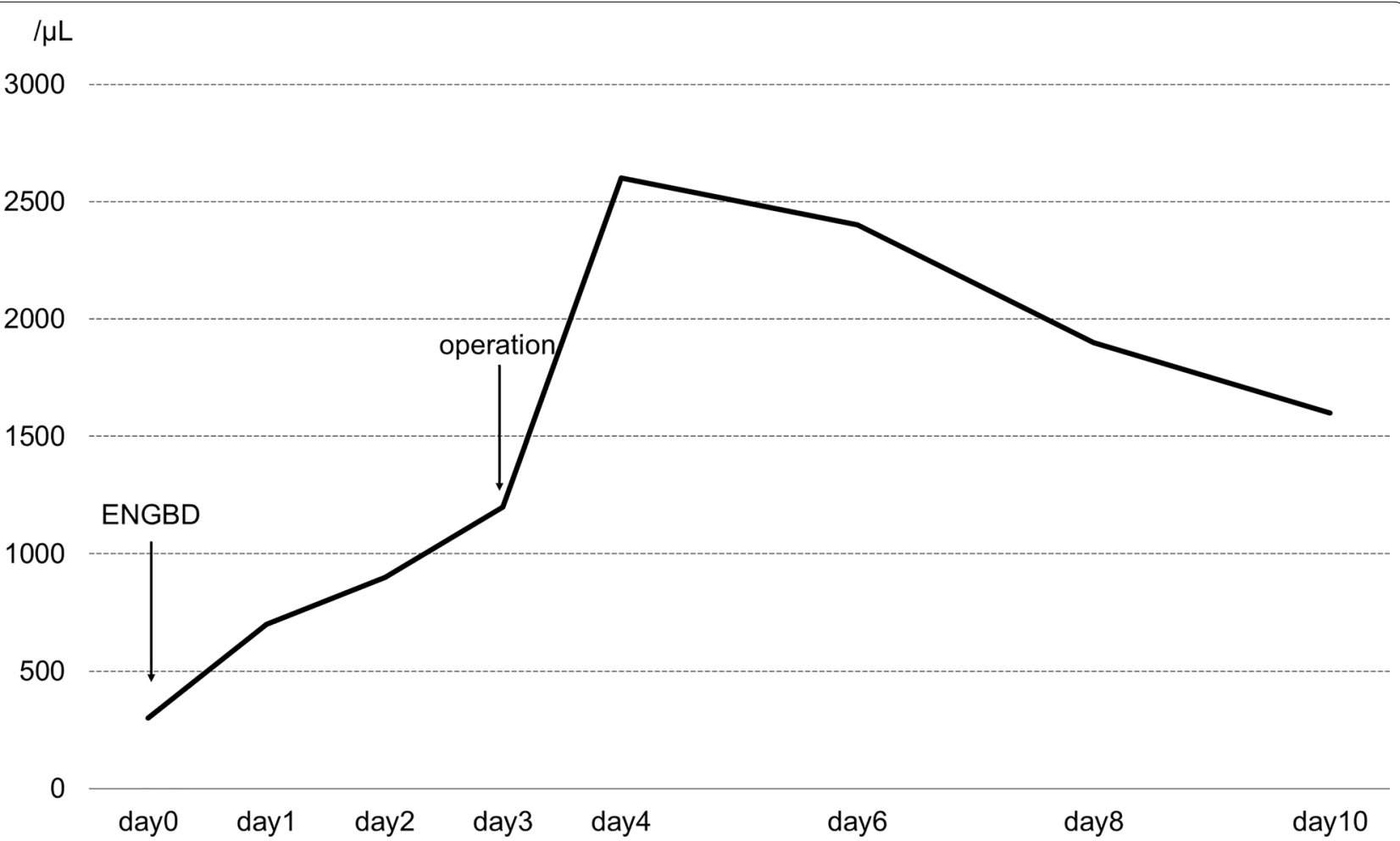

Fig. 2 Changes in the number of neutrophils. The vertical axis represents the number of neutrophils, the horizontal axis represents the number of days after hospitalization, and the polygonal line represents the fluctuation in the number of neutrophils 
Table 1 Summary of abdominal surgeries performed in emergency settings for patients with cyclic neutropenia

\begin{tabular}{|c|c|c|c|c|c|}
\hline Author/year & Age/sex & Disease & $\begin{array}{l}\text { Neutrophil count } \\
\text { at the first visit }\end{array}$ & Use of G-CSF & Prognosis \\
\hline Geelhoed et al./1973 [4] & 10/male & Neutropenic enterocolitis & 0 & No & Survival \\
\hline Langer et al./1990 [6] & 4/male & Neutropenic enterocolitis & 0 & No & Survival \\
\hline O'Hanrahan et al./1991 [5] & 14/female & Neutropenic enterocolitis & 200 & No & Survival \\
\hline Nedeljka Glavan et al./2015 [1] & 4/male & Acute appendicitis & 0 & Yes & Survival \\
\hline Saki Nishikawa et al./2020 & $31 /$ male & Acute cholecystitis & 300 & No & Survival \\
\hline
\end{tabular}

\section{Discussion}

Cyclic neutropenia is a rare autosomal dominantly inherited disorder. It is characterized by periodic neutropenia that recurs every 14-35 days, although most patients exhibit a cycle of about 21 days. The disorder most frequently starts in infancy or childhood. Most often, it is benign, and the symptoms ameliorate as the patient grows older [3]. The most common symptoms are fever, pharyngitis, gingivitis, and periodontitis. The patients may have more severe symptoms at the nadir of neutropenia, and infectious deaths have been reported in $10 \%$ of patients [3]. When surgery is required for these patients, possible worsening of the condition and severe postoperative complications should be considered due to neutropenia. Table1 shows data for abdominal surgeries performed in emergency settings for patients with cyclic neutropenia acquired via searching PubMed using the terms "cyclic neutropenia", and "operation" [1, 4-6]. In these cases, the absolute neutrophil count was as low as $0-200 / \mu \mathrm{L}$ at the first visit. Patients who received G-CSF were discharged without postoperative complications, but patients who did not receive G-CSF experienced complications such as enterocutaneous fistula, intestinal necrosis, and intra-abdominal abscess. Patients who experienced complications underwent reoperation at the time of neutrophil elevation and experienced positive outcomes moving forward. However, these postoperative complications can lead to potentially fatal peritonitis and sepsis. Neutrophil count is considered to be significantly involved in the postoperative course. Therefore, it is important to determine the timing of the surgery and prevent postoperative infections while taking into consideration the patient's general condition and absolute neutrophil count.

As a way of raising neutrophil count, recombinant G-CSF has proved efficacious. However, there are no universally accepted guidelines regarding the dose and duration of G-CSF treatment as well as no guidelines regarding the timing of surgery in the disorder.

Neutrophil count typically well exceeds $1500 / \mu \mathrm{L}$, once the neutrophil count is below $1000 / \mu \mathrm{L}$, the patient becomes susceptible to infections [2]. Patients respond to G-CSF doses in the range of $2-3 \mu \mathrm{g} / \mathrm{kg}$, administered subcutaneously either daily or on alternate days [7].

Our patient underwent ENGBD and antibiotics were administered. Gallbladder drainage is recommended as a useful treatment for patients with acute cholecystitis who are at high risk for surgery and who cannot be operated on immediately for reasons stipulated in the 2018 Tokyo Guidelines [8]. Inferred from the patient's neutropenia cycle, G-CSF was not provided before ENGBD because the neutropenic nadir had passed and the neutrophil count was relatively well maintained at $300 / \mu \mathrm{L}$. After ENGBD insertion, his general condition was stable and neutrophil count rose without the administration of G-CSF. Laparoscopic cholecystectomy was performed when his absolute neutrophil count was above $1000 / \mu \mathrm{L}$.

\section{Conclusion}

Determination of appropriate timing of surgery enables safe surgery for patients with neutropenia. Appropriate antibiotics and gallbladder drainage proved effective until neutrophil levels were sufficiently elevated.

\section{Abbreviations \\ ELA2: Elastase gene; CRP: C-reactive protein; CT: Computed tomography; ENGBD: Endoscopic naso-gallbladder drainage; G-CSF: Granulocyte colony- stimulating factor.}

\section{Acknowledgements \\ We would like to thank Editage (www.editage.com) for English language editing.}

\section{Authors' contributions}

$\mathrm{SN}$ and $\mathrm{MH}$ drafted the manuscript. SN, MM, HN, and TI contributed to patient care. SN and $\mathrm{MH}$ performed the literature search. SN, MM, HN, and TI participated in the critical revision of the manuscript. All authors read and approved the final manuscript.

\section{Funding}

The authors received no funding for this study.

Availability of data and materials

Data supporting the conclusions are included in the article.

Ethics approval and consent to participate

This study conforms to the provisions of the Declaration of Helsinki. The subject gave informed consent, and patient anonymity was preserved. 


\section{Consent for publication}

We obtained consent from the patient to publish this manuscript.

\section{Competing interests}

The authors declare that they have no competing interest.

\section{Author details}

${ }^{1}$ Department of Surgery, Hiroshima Prefectural Hospital, 1-5-54 Ujina-Kanda, Minami-ku, Hiroshima 734-8530, Japan. ${ }^{2}$ Department of Pathology, Hiroshima Prefectural Hospital, 1-5-54 Ujina-Kanda, Minami-ku, Hiroshima 734-8530, Japan.

Received: 26 November 2020 Accepted: 18 January 2021

Published online: 23 January 2021

\section{References}

1. Glavan N, Roganović J, Glavan-Gačanin L, Jonjić N. Appendectomy in a child with cyclic neutropenia in profound neutropenic episode. Ther Clin Risk Manag. 2015;11:1217-9.

2. Zergham AS, Acharya U. Cyclic neutropenia. StatPearls. Treasure Island: StatPearls Publishing LLC; 2020.

3. Lange RD, Jones JB. Cyclic neutropenia. Review of clinical manifestations and management. Am J Pediatr Hematol Oncol. 1981;3(4):363-7.
4. Dale DC, Cottle TE, Fier CJ, Bolyard AA, Bonilla MA, Boxer LA, et al. Severe chronic neutropenia: treatment and follow-up of patients in the Severe Chronic Neutropenia International Registry. Am J Hematol. 2003;72(2):82-93

5. Geelhoed GW, Kane MA, Dale DC, Wells SA. Colon ulceration and perforation in cyclic neutropenia. J Pediatr Surg. 1973;8(3):379-82.

6. O'Hanrahan T, Dark P, Irving MH. Cyclic neutropenia-unusual cause of acute abdomen. Report of a case. Dis Colon Rectum. 1991;34(12):1125-7.

7. Langer JC, Papa MZ, Hoffman MA, Loeff DS, Pearl RH, Filler RM. Cyclic neutropenia with colonic perforation and nonhealing colocutaneous fistula. J Pediatr Surg. 1990;25(3):346-8.

8. Horwitz MS, Duan Z, Korkmaz B, Lee HH, Mealiffe ME, Salipante SJ. Neutrophil elastase in cyclic and severe congenital neutropenia. Blood. 2007;109(5):1817-24

9. Ito K, Fujita N, Noda Y, Kobayashi G, Kimura K, Sugawara T, et al. Percutaneous cholecystostomy versus gallbladder aspiration for acute cholecystitis: a prospective randomized controlled trial. AJR Am J Roentgenol. 2004;183(1):193-6.

\section{Publisher's Note}

Springer Nature remains neutral with regard to jurisdictional claims in published maps and institutional affiliations.

\section{Submit your manuscript to a SpringerOpen ${ }^{\circ}$ journal and benefit from:}

- Convenient online submission

$\checkmark$ Rigorous peer review

- Open access: articles freely available online

- High visibility within the field

- Retaining the copyright to your article

Submit your next manuscript at $\gg$ springeropen.com 